\title{
Artigos
}

\section{Implementação da Política Nacional de Saúde Integral de Lésbicas, Gays, Bissexuais, Travestis e Transexuais (PNSI LGBT) no Paraná, Brasil*}

Implementation of the National Policy for the Comprehensive Healthcare of Lesbians, Gays, Bisexuals, Transvestites and Transsexuals (PNSI LGBT) in Paraná, Brazil (abstract: p. 16)

Implementación de la Política Nacional de Salud Integral de Lesbianas, Gais, Bisexuales, Travestis y Transexuales (PNSI LGBT) en el Estado de Paraná, Brasil (resumen: p. 16)

Amanda de Cassia Azevedo da Silva ${ }^{(a)}$

<sucessocomprosperidade@gmail.com> (i)

Anelise Montañes Alcântara(b)

<liumontanes@gmail.com> (D)

Daniel Canavese de Oliveira ${ }^{(\mathrm{c})}$

<daniel.canavese@gmail.com> iD

Marcos Claudio Signorelli ${ }^{(\mathrm{d})}$

<signore@ufpr.br> (ID)
* Estudo desenvolvido como parte do projeto de mestrado da primeira autora, que contou com bolsa da Coordenação de Aperfeiçoamento de Pessoal de Nível Superior (Capes). Pesquisa financiada pelo Ministério da Saúde.

(a) Enfermeira. Curitiba, PR, Brasil.

(b) Escola de Saúde Pública do Paraná. Curitiba, PR, Brasil.

(c) Universidade Federal do Rio Grande do Sul. Porto Alegre, RS, Brasil.

0 artigo trata de tema urgente e relevante referente aos desafios e às potencialidades para implementação de políticas públicas de saúde destinadas à população de lésbicas, gays, bissexuais, travestis e transexuais (LGBT). Investigou-se a implementação da Política Nacional de Saúde Integral de Lésbicas, Gays, Bissexuais, Travestis e Transexuais (PNSI LGBT) no Paraná, a partir de quatro grupos focais com 48 participantes, em uma abordagem qualitativa. Participaram dos grupos profissionais e gestores (as)do Sistema Único de Saúde (SUS), da Secretaria da Saúde do Estado do Paraná, profissionais da rede intersetorial e representantes de movimentos sociais LGBT. Foram definidos quatro eixos de análise: acesso da população LGBT à atenção integral à saúde; ações de promoção e vigilância em saúde; educação permanente e educação popular em saúde; e monitoramento e avaliação das ações de saúde. Concluiu-se que há lacunas na implementação da política, nos três níveis de atenção à saúde da população LGBT.

Palavras-chave: Política pública. Equidade em saúde. Pessoas LGBT. Sistema Único de Saúde.

Silva ACA, Alcântara AM, Oliveira DC, Signorelli MC. Implementação da Política Nacional de Saúde Integral de Lésbicas, Gays, Bissexuais, Travestis e Transexuais (PNSI LGBT) no Paraná, Brasil. Interface (Botucatu). 2020; 24: e190568 https://doi.org/10.1590/Interface.190568 


\section{Introdução}

A PNSI LGBT ${ }^{1}$ foi formulada em 2011, sendo formada por diretrizes, cuja instrumentalização requer planos, estratégias e metas sanitárias ${ }^{1}$. A política reconhece a existência de efeitos perversos dos processos de discriminação, violências e exclusão sobre a saúde da população de LGBT e, visando sua superação, orienta-se para promoção da equidade em saúde. Destaca, ainda, que orientação sexual e identidade de gênero são reconhecidas pelo Ministério da Saúde como determinantes e condicionantes da situação de saúde, na medida em que intolerância, estigma e exclusão social podem ser geradoras de sofrimento e limitadoras do acesso da população LGBT aos cuidados de saúde.

Segundo relatório do Grupo Gay da Bahia $(\mathrm{GGB})^{2}$, a expectativa de vida de uma pessoa trans (travestis e transexuais) no Brasil é de 35 anos e o país registrou 445 casos de assassinatos de LGBT em $2017^{2}$. O número representa uma vítima a cada 19 horas, o maior número de casos de morte relacionados à LGBTfobia desde que o monitoramento anual começou a ser elaborado pela entidade, há 38 anos. LGBTfobia é o preconceito e a discriminação ocorrida em virtude da orientação sexual ou da identidade de gênero, ou seja, vai além da homofobia, lesbofobia, gayfobia, bifobia e transfobia ${ }^{3}$.

A população LGBT sofreu 699 ocorrências de violência em 2016, de acordo com o Ministério dos Direitos Humanos ${ }^{4}$, enquanto, em 2018, foram 420 mortes $^{5}$. Tais casos podem estar subnotificados, pois, enquanto deveriam ser tratados como crimes de ódio, muitas vezes são abordados como infraçóes comuns ou sequer são notificados ${ }^{2}$. Portanto, percebe-se que o cenário acerca da saúde e da vida de pessoas LGBT não é favorável no Brasil, uma vez que é o país que mais assassina no mundo essa população.

Alguns estudos ${ }^{6-10}$ sobre a PNSI LGBT revelam que, apesar dos avanços, há aspectos a serem aprimorados, como a necessidade de que os princípios de universalidade, integralidade e equidade sejam concretizados em políticas públicas que promovam o enfrentamento da LGBTfobia.

Vilasbôas et al. ${ }^{11}$ abordam que a análise da implementação de políticas de saúde pode elucidar as formas como ocorrem os vínculos entre a criação de instruçôes políticas e sua prática nos serviços de saúde. Desse modo, torna-se indispensável explorar a implementação da PNSI LGBT ${ }^{1}$. Logo, este estudo objetivou investigar a implementação da política no âmbito do estado do Paraná, privilegiando as vozes do(a)s atores(atrizes) que trabalham com sua implementação, incluindo gestor(a)s e profissionais do SUS, assim como profissionais da rede intersetorial e representantes dos movimentos sociais LGBT.

A pergunta que norteou este estudo foi: quais dificuldades e conquistas na implementação da PNSI LGBT no estado do Paraná são reveladas a partir da ótica do(a)s atores(atrizes) implicado(a)s no processo de implementação? Espera-se, por meio desta investigação, que se reflita sobre o processo de implementação e que sejam aprimoradas as condições de saúde da população LGBT, aplicando de fato todo o constructo legal formador dessa política. 


\section{Metodologia}

Este estudo possui abordagem qualitativa. Optou-se pela pesquisa qualitativa, pois ela permite uma visão mais profunda do cenário pesquisado e possibilita captar movimentos sociais e a percepção dos profissionais de saúde e de gestores do SUS a respeito da implementação da PNSI LGBT ${ }^{1}$ no Paraná. Morgan ${ }^{12}$ interpreta o grupo focal (GF) como uma técnica de pesquisa qualitativa derivada das entrevistas grupais, que coleta informaçóes por meio de relaçóes grupais.

Os critérios nos quais o estudo se ancorou estabelecem os meios que fazem parte da PNSI LGBT, os quais estão definidos pelos eixos do plano operativo da PNSI LGBT, consistindo em: Eixo 1 - Acesso da população LGBT à atenção integral à saúde; Eixo 2 - Ações de promoção e vigilância em saúde para a população LGBT; Eixo 3 - Educação permanente e educação popular em saúde com foco na população LGBT; Eixo 4 - Monitoramento e avaliação das açốes de saúde para a população LGBT.

Para a coleta de dados, fizeram parte dos quatro GFs 48 pessoas provenientes de vários locais do estado, incluindo: representantes de movimentos sociais LGBT; gestores; e profissionais da saúde do SUS e da rede intersetorial. O roteiro dos GFs foi elaborado e validado em conjunto com gestores da Secretaria de Estado da Saúde do Paraná (SESA/PR), adotando-se pressupostos da pesquisa-ação participativa ${ }^{13}$. Os facilitadores de cada GF pactuaram previamente com o desenvolvimento e a metodologia.

O recrutamento de participantes foi realizado a partir da apresentação do projeto de pesquisa à coordenação da equipe da SESA/PR e posterior convite para os trabalhadores e gestores. Também foram enviados convites aos representantes do movimento social, controle social e protagonistas da rede intersetorial. Durante a coleta de dados, designaram-se os participantes aleatoriamente em cada GF. As falas que afloraram dos GFs foram gravadas, transcritas, codificadas, categorizadas tematicamente, analisadas e comparadas com interpretações relativas aos quatro eixos da PNSI LGBT.

Segundo a análise dos participantes desta pesquisa, ainda é baixo o número de homens envolvidos com a temática em foco. Do total de 48 participantes dos GFs, 46 são mulheres, evidenciando um perfil feminino de engajamento neste estudo. Além disso, 43 pessoas se autodeclararam heterossexuais. A maioria dos participantes eram psicólogos e enfermeiros. A faixa de idade predominante foi de trinta a 39 anos, e a escolaridade prevalente foi de ensino superior com especialização. Há de se ressaltar que Curitiba foi a cidade que mais teve representação, pela facilidade de acesso, uma vez que o evento que sediou os GFs ocorreu nesta cidade.

A pesquisa ocorreu após assinaturas do Termo de Consentimento Livre e Esclarecido (TCLE), sendo aprovada pelos Comitês de Ética em Pesquisa da Universidade Federal do Paraná (Parecer no 2.632.685) e do Comitê de Ética da Secretaria de Saúde do Estado do Paraná (Parecer no 2.786.173). Este artigo integra uma dissertação de mestrado em Saúde Coletiva e faz parte de um projeto interinstitucional que investiga a implementação da PNSI LGBT nos três estados da região sul do país, com apoio do Ministério da Saúde. 


\section{Resultados e discussão}

Para a transcrição das falas, os participantes $(\mathrm{P})$ não foram identificados e as transcriçôes estão especificadas por GF.

\section{O acesso da população LGBT à atenção integral à saúde}

Este tópico aborda barreiras encontradas no acesso referidas à discriminação, preconceito institucional e desigualdades da população LGBT nos serviços de saúde no SUS. A atenção integral deve garantir respeito e prestação de serviços de saúde com qualidade, resolvendo suas demandas e necessidades específicas. Consideram-se inúmeros fatores na determinação social da saúde e no processo de sofrimento e adoecimento, como a discriminação por orientação sexual e por identidade de gênero. A necessidade de ampliação do acesso ao processo transexualizador (PrTr) também foi abordada neste eixo ${ }^{1}$.

A pesquisa identificou a existência de desigualdades e acesso iníquo desse grupo populacional aos serviços de saúde, como relatam Ferraz et al. ${ }^{14}$. Guimarães et al. ${ }^{15}$ acentuam que obstruções à efetivação do princípio da universalidade são estabelecidas por dificuldades simbólicas ao acesso, determinadas pelo preconceito e pelo estigma, conforme observado a seguir:

Pelos meus valores condeno uma população que é diferente de mim, independentemente do seu segmento populacional. Se eu tenho julgamentos morais que uma mulher não pode ter relação sexual com outra mulher, eu não te tratarei bem. (P GF1)

Albuquerque et al. ${ }^{16}$ lembram que o acesso desse segmento aos serviços de saúde representa uma condição de vulnerabilidade para a população LGBT, pois é retratado como opressor e eliminatório, destacado por impedimentos, preconceito, discriminação, intolerância e agressóes verbais praticadas pelos profissionais.

A Organização das Naçóes Unidas $(\mathrm{ONU})^{17}$ destaca o estigma e a discriminação como graves empecilhos para o acesso e o uso dos serviços de saúde pelo público LGBT. O estigma e a ignorância em relação à identidade de gênero são frequentes na sociedade e nos serviços de saúde. A discriminação pode promover negação de provimento de cuidados, assistência precária e tratamento ofensivo ou arbitrário ${ }^{16}$.

Um médico mais antigo pede para colocar paciente gay para outro profissional atender dizendo que esses pacientes “cantam” ele. Eu observo que é uma desculpa porque, na verdade, isso é preconceito. (P GF4)

Villela ${ }^{18}$ assevera que o estigma age com força superior ou inferior nas relaçôes sociais, dependendo da potência de desigualdade processada, especificamente. Ele influencia no direito à saúde, assim como na limitação do acesso aos serviços e entendimentos de saúde, afetando o uso da cidadania e de direitos, além da possibilidade de gozar plena e dignamente 
a vida. Por outro lado, Silva et al. ${ }^{19}$ salientam que o nome social se tornou uma forma de combate à discriminação e garantia de que os direitos no SUS serão assegurados, face à exclusão social e preconceito.

A gente enfrenta uma problemática de discriminação institucionalizada principalmente pelas populaçóes que se encaixam em estereótipos mais óbvios. A discriminação de travestis e transexuais é uma constante de reclamações. (P GF3)

A utilização do nome social nos serviços de saúde é efetivada pela Portaria no 1.820/2009. Deve existir no documento do usuário um campo para se registrar o nome social, independentemente do registro civil, assegurando-se o uso do nome adotado, não podendo ser identificado por número, nome, CID ou formas desrespeitosas ou preconceituosas ${ }^{20}$.

Para Rocon at al. ${ }^{10}$, o desprezo ao nome social figura como entrave decisivo ao acesso universal, integral e equitativo no SUS, junto com a trans/travestifobia nos sistemas de saúde e o diagnóstico patologizante no PrTr. ${ }^{9}$

[..] nome social está dentro do prontuário do paciente. Então todo mundo sabe. [...] E aí, ele chega na recepção, e a identidade é a primeira coisa que o auxiliar de enfermagem vai pedir. A pessoa que tem um certo perfil vai dar valor, mas, aquele que não tem, vai barrar até mesmo de propósito. (P GF3)

Dessa forma, Popadiuk et al. ${ }^{6}$ refletem se as equipes da atenção primária estariam aptas para cuidar do público trans:

Na prática é até difícil você conversar com uma equipe sobre como usar o nome social. Nós temos uma mulher trans no nosso serviço que está nos ensinando. É importante reconhecer "não saber". (P GF1)

Arán ${ }^{21}$ assinala que a transexualidade feminina pode causar profundo sofrimento dessas pessoas, principalmente devido à desinformação, à inaptidão e à inabilidade dos sistemas de saúde para cuidá-las. Bezerra et al. ${ }^{22}$ destacam que o sofrimento dos homens trans transita por contextos de vulnerabilidade familiar e social que revertem em carências; traumas; e adoecimento físico e mental causados pela violência e desrespeito ao nome social e ao direito à identidade de gênero. A família e os serviços de saúde e de ensino deveriam garantir direitos, mas são seus maiores transgressores ${ }^{22}$. Essa exposição exemplifica o que foi exposto: "A pessoa tem o acesso, busca o serviço, é discriminada e violada. Isso deixa-as vulneráveis psicologicamente" (P GF3).

Nesta pesquisa, o Centro de Pesquisa e Atendimento pra Transexuais e Travestis (CPATT) foi uma experiência muito citada nos GFs. Criado em 2013, com a intenção de subsidiar os atendimentos do SUS na atenção secundária para pessoas trans, o CPATT situa-se em Curitiba e é o único centro do estado habilitado para oferecer a hormonioterapia com acompanhamento multiprofissional especializado: 
Precisamos de ajuda. O CPATT é o único ambulatório especializado do Estado e lá atendemos pessoas do estado todo e não damos conta de toda demanda. Muitas pessoas viajam um, dois dias inteiros para vir para uma consulta e só conseguem vir uma vez por mês, sem conseguir manter um acompanhamento mais próximo. Então seria importante que existissem outros polos de atendimento. (P GF1)

Considerando o relato e o objetivo da equipe multiprofissional do CPATT em atender integralmente travestis e transexuais, é importante ressaltar algumas falas nos GFs: o CPATT é reconhecido como importante conquista para saúde da população trans no Paraná; todavia, há preocupaçóes com a elevada demanda do ambulatório e grande fila de espera; algumas consultas no CPATT poderiam ter intervalo de tempo menor, dependendo do caso; a criação de polos de atendimento CPATT no interior do estado poderia diminuir as filas de espera, facilitando acessos; os encaminhamentos ao CPATT são pouco conhecidos por parte da rede intersetorial. Por fim, foi assinalada a falta de hospital que realize cirurgias do PrTr no estado, cujo acompanhamento pré e pós-operatório poderia ser feito no CPATT.

De acordo com Prado e Sousa ${ }^{23}$, o usuário LGBT pode sofrer discriminações e estigmatizações, traduzidas em barreiras no acesso aos serviços de saúde, que podem influenciar na procura por atendimentos de serviços clandestinos, os quais, pela precariedade de forma generalizada, podem oferecer risco e, sobretudo, elevar os padróes de vulnerabilidade. As discriminaçôes e violências a que estes indivíduos são expostos diariamente, inclusive nas instituiçôes de cuidado em saúde, revelam a necessidade de mudanças nas práticas do cuidado em saúde, que precisam ser voltadas para um atendimento ético e isento de discriminações ${ }^{23}$.

O preconceito, que dificulta o ingresso do público LGBT aos serviços de saúde, foi mencionado nessa perspectiva, uma vez que esse acesso já é muito difícil e, quando existe discriminação, essas pessoas são ainda mais afastadas da atenção primária.

\section{Ações de promoção e vigilância em saúde para a população LGBT}

A PNSI LGBT ${ }^{1}$ salienta que esse eixo trata do aprimoramento dos métodos de vigilância em saúde, incluindo os campos orientação sexual e identidade de gênero; e o desenvolvimento de estratégias para qualificar todo o processo de desenvolvimento das ações de promoção e vigilância para LGBT. A possibilidade de se obter esses dados tem como potência o fato de qualificar indicadores de saúde e melhor planejar ações de prevenção e promoção da saúde $\mathrm{LGBT}^{24}$. A violência contra LGBT deve necessariamente ser notificada por meio da ficha de notificação de violências interpessoais e autoprovocadas, sendo ou não motivada por LGBTfobia e seu registro no Sistema de Informação de Agravos de Notificação (SINAN) 25 : 
Trabalho num setor que recebe fichas de notificação. E a gente percebe uma diferença bem clara quanto à pessoa na entrevista. Tu vais avaliar a ficha, o campo de orientação sexual: quando o profissional sabe que a pessoa veio acompanhada do marido, da esposa, bota heterossexual, mas nem perguntou e quando ela tem dúvida ela coloca como ignorado, mas não pergunta [...]. (P GF1)

Atitudes como essa contribuem para a subnotificação e baixa qualidade dos bancos de dados. O SUS vem criando mecanismos de registros, a exemplo dessa ficha, mas muitos profissionais, quando notificam, não atentam para a qualidade do preenchimento, o que gera escassez de dados sobre a violência motivada por LGBTfobia. De acordo com o Ministério dos Direitos Humanos³ em 2016, houve 104 ocorrências de violências registradas contra travestis, 103 contra transexuais, 318 contra gays, 123 contra lésbicas e 51 contra bissexuais. Mesmo com aumento de casos de violência LGBTfóbica no Brasil, é alta a subnotificação da violência contra LGBT $^{3}$.

Avaliando pela ficha do SINAN, é grande a tentativa de suicídio entre a população LGBT. A gente descobre que na ficha não tem nada naqueles campos e a violência foi cometida pelo quê? No fim, a gente não sabe por que a pessoa cometeu suicídio. Nos hospitais eles não perguntam, por um tabu, e nós não temos dados subnotificados. (P GF1)

Para Araújo et al. ${ }^{26}$, o vínculo entre profissional e usuário é indispensável para a qualidade dos cuidados de saúde. Contudo, há vulnerabilidade nesse contato, especialmente na comunicação, em que demandas essenciais sobre sexualidade podem ser ocultadas, refletindo em lacunas na promoção de saúde.

As açốes de promoção de saúde para LGBT citadas pelos participantes dos GFs envolvem: o apoio matricial, mencionado como uma ferramenta contra o preconceito dos profissionais em relação aos usuários LGBT; a Parada do Orgulho LGBT, responsável por proporcionar visibilidade a esse público na reivindicação de direitos, inclusive no âmbito da saúde, além de propagar conhecimentos importantes aos participantes; o CPATT como promotor de saúde da população trans; e a força dos movimentos sociais na luta a favor de direitos que promovam saúde ao grupo. Sintetizou-se a promoção de saúde com a narrativa do P GF1: "Deve-se promover a saúde da população LGBT, abandonando a ideia que o indivíduo só precisa do serviço de saúde quando adoece”.

\section{Educação permanente e educação popular em saúde com foco na população LGBT}

Este eixo aborda métodos que visem à educação em saúde para gestores e profissionais de saúde; açốes que possibilitem educação em saúde para o controle social; e inclusão da educação nas rotinas dos serviços de saúde voltada para o fim do preconceito contra LGBT, sempre se preocupando com o combate às discriminaçôes de gênero, orientação sexual, raça, cor, etnia e território e com as singularidades em saúde da população LGBT ${ }^{1}$. 
O Ministério da Saúde ${ }^{27}$ explicita que, como forma de promoção e educação em saúde, ações nesse âmbito revelam o investimento na educação permanente de profissionais sobre a política de saúde $\mathrm{LGBT}^{1}$. Açốes da SESA/PR e da academia foram mencionadas na pesquisa.

[...] a Universidade Federal do Paraná começou a fazer vários programas de formação [...]. Eu era extremamente ignorante na questão LGBT e a partir do momento que eu fiz o curso [...] fui conhecendo toda temática. (P GF1)

Por outro lado, o Relatório do I Seminário Nacional de Saúde LGBT ${ }^{28}$ informou que falta capacitação dos gestores e profissionais; existe uma carência de organização de cursos para sensibilização e esclarecimentos sobre saúde LGBT; há a necessidade de maior diálogo e agregação entre os Ministérios da Saúde e da Educação, para recomendar modificações nos currículos dos cursos da saúde, visando à formação de profissionais habilitados a trabalhar com o público LGBT ${ }^{28}$. A medida é eminentemente necessária, apoiada por Negreiros et al. ${ }^{29}$, que expóem relatos de seu estudo recente com médicos da atenção primária, sinalizando deficiências da grade curricular dos cursos da saúde e a indispensabilidade de capacitaçóes relacionadas com a temática.

A invisibilidade é algo muito presente [...], não existe disciplina que nos ensine sobre o tema na academia, não falamos sobre isso no trabalho, não sabemos como agir com o usuário LGBT. É tudo novo, toda informação é bem-vinda [...]. (P GF2)

$\mathrm{Na}$ academia não tem grade curricular falando sobre, mas alguns professores são sensíveis à causa LGBT e acabam colocando como trabalho para os acadêmicos, onde eles têm que pesquisar sobre a população para semana acadêmica, simpósio, para eventos que acontecem dentro das universidades. (P GF3)

Albuquerque et al. ${ }^{16}$ revelam essa dificuldade ao enfatizarem que o tema permanece marginalizado e excluído das grandes discussóes, sobretudo na academia e na atenção primária. Ressaltam que estratégias que objetivam a discussão de peculiaridades, como atenção à saúde desses grupos, devem ser estimuladas para qualificar o atendimento.

Invisibilidade é algo muito presente. $\mathrm{Na}$ academia não é falado. No trabalho não é falado. Quando chega um usuário LGBT a gente não sabe como agir. Os funcionários começam a brincar [...]. (P GF2)

Eu mesmo conheço pouco da política. [...] há uma invisibilidade muito grande [...] falta de capacitação. Eu peço que invista na capacitação de profissionais, roda de conversa. (P GF1) 
Mello et al. ${ }^{7}$, Cardoso et al. ${ }^{30}$ e Carvalho et al. ${ }^{31}$ defendem a necessidade de capacitação de profissionais da saúde para o atendimento não discriminatório da população LGBT, pelas dificuldades que esse público enfrenta nos serviços de saúde. Rocon et al. ${ }^{10}$ sustentam a utilidade de problematizar, junto com a equipe de saúde, as consequências da abordagem de gênero binário e da heteronormatividade.

\section{Monitoramento e avaliação das ações de saúde para a população LGBT}

Neste eixo, a PNSI LGBT ${ }^{1}$ refere a necessidade de indicadores de monitoramento e avaliação, contemplando dados sobre morbimortalidade e acesso dessas populaçôes à atenção integral à saúde, considerando as prioridades e metas dos planos estaduais e municipais de saúde.

Negreiros et $\mathrm{al}^{29}$ apontam como as discussões sobre população LGBT ainda vinculam com intensidade a temática do HIV/Aids, relacionada à vulnerabilidade a que essa população foi sujeitada historicamente.

Trabalhei no Centro de Orientação e Aconselhamento de Curitiba para testagem rápida, mas durante vários dias a gente recebia a população LGBT que tinha tentado o atendimento em alguma unidade de saúde e que a partir do momento que falava sobre sua orientação sexual, imediatamente encaminhavam para lá, como se a população LGBT só tivesse questôes de doenças sexualmente transmissíveis. (P GF1)

Outra questão é uma taxatividade de que, quando se fala em LGBT, as pessoas lembram de HIV e não pensam em saúde integral. (P GF 3)

Homossexuais masculinos, além de vítimas da violência e homicídios homofóbicos, como mostram os dados do Ministério dos Direitos Humanos ${ }^{3}$, por passarem por experiências discriminatórias na sociedade e nos serviços de saúde, podem sofrer baixa autoestima; sentimento de culpa; insegurança; isolamento social; dificuldade de estabelecer e manter relaçôes amorosas; depressão; e maior risco para suicídio, como citam Cardoso et al..$^{30}$. A cartilha do Ministério da Saúde "Atenção Integral à Saúde de Homens Gays e Bissexuais" 32 revela que o suicídio faz parte de uma gama de agravos evitáveis, atrelados ao adoecimento mental, que podem ser suscitados pela homofobia, refletindo carência de acesso aos programas de saúde mental específicos para gays, assim como a falta de interlocução com outras políticas de saúde. Isso pode ser percebido no seguinte relato: "Não se fala em população LGBT na saúde mental, nem na academia, nem nos cursos e atualizações” (P GF1).

Ainda em relação ao monitoramento e avaliação de ações de saúde, no caso específico das mulheres, o Dossiê da Rede Feminista de Saúde ${ }^{33}$ mostra que 40\% das mulheres lésbicas ou bissexuais não revelam sua orientação sexual nas consultas; que $28 \%$ das mulheres que revelam relatam ter um atendimento mais rápido; e que a cobertura do exame de papanicolau é menor em mulheres que fazem sexo com mulheres, pois a proporção encontrada foi $66,9 \%$, contra $89,7 \%$ nas heterossexuais. Muitas lésbicas 
relatam discriminação ao acessarem serviços de saúde e referem ser desmotivadas a procurar cuidados à saúde; $\mathrm{e}$, quando os procuram, suas demandas não são abordadas. Os motivos elencados nos GFs para menor busca aos serviços de saúde foram: discriminação, despreparo dos profissionais na atenção às suas particularidades, dificuldades em assumirem sua orientação sexual e negação de aceitar o risco de desenvolver doenças, como pode ser exemplificado a seguir:

[...] quando você fala de mulheres lésbicas e bissexuais, não se tem nada. Muitas mulheres têm tido câncer de colo de útero por falta de realização de papanicolau. (P GF3)

Por outro lado, estratégias positivas foram citadas nesta pesquisa. Elas visam prevenir o HIV/Aids e outras infecçôes sexualmente transmissíveis, bem como reduzir o diagnóstico tardio dessas doenças, ampliando a testagem e incentivando o tratamento precoce. Dentre essas ações, destacam-se testes rápidos para a detecção do HIV/Aids e aconselhamento ${ }^{32,34,35}$. Também há o apoio da SESA/PR, em relação à PNSI LGBT, na dispensação de hormônios gratuitamente; e o trabalho dos departamentos de Divisão de Atenção às Comunidades Vulneráveis e do Programa DST-Aids.

Além disso, foi realçada a existência de dois comitês LGBT na estrutura governamental do estado do Paraná, que servem como controle social e multiplicadores de conhecimento entre profissionais e movimentos sociais: o "Comitê de Acompanhamento da Política de Promoção e Defesa dos Direitos da população LGBT do Estado do Paraná”36 (Secretaria de Justiça) e o "Comitê Técnico de Saúde Integral das Pessoas LGBT" 37 (Secretaria de Saúde):

Temos dois comitês LGBT; um pertence à saúde [...] e o comitê intersetorial, das secretarias de trabalho, direitos humanos, justiça. Uma das nossas discussões é a de transmitir as informações que vêm em relação à população LGBT dentro de toda a secretaria, de uma forma didática, que a pessoa compreenda e consiga repassar [...]. (P GF 2)

Considerando a abordagem deste eixo e sobrelevando a intenção de divulgar e aumentar as informaçốes acerca do monitoramento, avaliação e implementação das açôes de saúde sobre a população LGBT no Paraná, destaca-se que os resultados deste estudo geraram o "Relatório Técnico de Análise Qualitativa da Implementação da Política Nacional de Saúde Integral da População LGBT no Estado do Paraná”38.

\section{Considerações finais}

Esta pesquisa deu vez e voz aos protagonistas que sustentam a implementação da PNSI LGBT no estado do Paraná, desnudando situaçóes vivenciadas pelo segmento LGBT nos serviços de saúde. Em relação ao acesso da população LGBT à atenção integral à saúde, o estudo permitiu o reconhecimento de dificuldades no decorrer da rede de atenção em saúde; falta de informação de trabalhadores; impasses nos encaminhamentos entre atenção primária e secundária; obstáculos no acesso aos serviços de saúde na atenção primária; e preconceito dos funcionários em relação aos 
usuários LGBT. Tais identificações configuram diferentes situações de insensibilidades, conforme experiências relatadas nos GFs e, independentemente da orientação sexual ou identidade de gênero, do receio e do estigma, são motivos de muitas pessoas evitarem informar dados sobre sua saúde sexual para profissionais de saúde. Outro aspecto relevante diz respeito à insegurança de alguns(mas) profissionais da saúde na abordagem de pessoas LGBT, fruto da falta de formações/capacitaçôes específicas.

Os relatos revelaram que serviços de saúde para LGBT no Paraná são permeados por situaçóes de estigma, que prejudicam o acesso e permanência de LGBT nos serviços do SUS. Postula-se a necessidade da promoção constante de ferramentas para melhoria dos processos de trabalho e mudança de práticas profissionais para com o público LGBT.

Dentre as açôes de promoção e vigilância em saúde para LGBT, destacou-se a "Ficha de Notificação de Violências", ao incorporar os campos “identidade de gênero", "orientação sexual" e "nome social" da vítima, além da LGBTfobia entre as motivações de violência. Contudo, é preciso qualificar o preenchimento desses campos para evitar a subnotificação.

A educação permanente e educação popular em saúde devem ser pautadas na humanização; na dignidade da pessoa humana; e no respeito ao nome social e às identidades de gênero em açóes de educação em saúde e na busca por um atendimento equânime. Discriminação, óbices de diálogo entre profissionais da saúde e LGBT, além da violação quanto ao uso do nome social, manifestam-se como entraves ao acesso de pessoas LGBT aos serviços de saúde, contribuindo para o adoecimento, na medida em que os nega e dificulta cuidados em saúde. É essencial a inclusão desta temática nos currículos da saúde, para que todos os profissionais da saúde tenham o conhecimento dos fundamentos necessários para proporcionar acolhimento, prevenção, promoção e terapêutica de qualidade à população LGBT.

No que se refere ao monitoramento e à avaliação das ações de saúde, destaca-se positivamente o papel do CPATT, referência em atenção secundária para travestis e transexuais, assim como as capacitaçóes de profissionais, as campanhas promovidas pelo Ministério da Saúde e pela SESA/PR, além da existência de dois comitês de saúde LGBT no estado. Nesse eixo, mostra-se necessário o estudo em outros cenários que contribuam para a monitoramento, implementação e avaliação da PNSI LGBT.

Os achados desta pesquisa estão em consonância com as afirmações de Albuquerque et al. ${ }^{16}$ de que a população LGBT não tem suas necessidades de saúde plenamente amparadas por estar submetida à discriminação, junto com o receio de que revelar sua orientação sexual em serviços de saúde traga uma repercussão negativa ao atendimento.

Assim, é imperiosa a efetivação dos princípios constitutivos do SUS de universalidade, integralidade e equidade, expressos em políticas públicas que de fato promovam o enfrentamento da homofobia e da heteronormatividade nos serviços de saúde, assim como dos eixos da PNSI LGBT.

Este estudo teve como principais limitaçóes o fato de apresentar um retrato particular daquele momento histórico e incluir participantes que puderam participar fisicamente dos GFs, em horário comercial e no município de Curitiba. Portanto, retratou o olhar dos participantes dos GFs, não sendo possível extrapolar para outras realidades. Espera-se que este estudo possa fomentar análises comparativas em outras unidades da federação. 


\section{Filiação}

(d) Câmara de Saúde Coletiva, Setor Litoral, Universidade Federal do Paraná, Matinhos, PR, Brasil.

\section{Contribuições dos autores}

Todos os autores participaram ativamente de todas as etapas de elaboração do manuscrito.

\section{Agradecimentos}

Ao Ministério da Saúde, à SESA/PR e às (aos) pesquisadoras (es) que colaboraram na condução dos GFs.

\section{Direitos autorais}

Este artigo está licenciado sob a Licença Internacional Creative Commons 4.0, tipo BY (https://creativecommons.org/licenses/by/4.0/deed.pt_BR)..

\section{(cc) BY}

\section{Referências}

1. Brasil. Ministério da Saúde. Secretaria de Gestão Estratégica e Participativa. Política nacional de saúde integral de lésbicas, gays, bissexuais, travestis e transexuais. Brasília: Ministério da Saúde; 2013.

2. Mott L, Michels E, Paulinho. Pessoas LGBT mortas no Brasil: relatório 2017 [Internet]. Salvador: GGB; 2017 [citado 25 Maio 2019]. Disponível em: https:// grupogaydabahia.files.wordpress.com/2020/03/relatorio-2017.pdf

3. Brasil. Conselho Nacional de Combate à Discriminação e Promoção dos Direitos da população LGBT. Relatório final: 3a conferência nacional de políticas públicas de direitos humanos de lésbicas,gays, bissexuais, travestis e transexuais [Internet]. Brasília: CNCD/LGBT; 2016 [citado 25 Maio 2019]. Disponível em: http://www.sdh.gov.br/ sobre/participacao-social/cncd-lgbt/relatorio-final-3a-conferencia-nacional-lgbt-1

4. Brasil. Ministério dos Direitos Humanos. Secretaria Nacional de Cidadania. Violência LGBTfóbicas no Brasil: dados da violência. Brasília: Ministério dos Direitos Humanos; 2018.

5. Michels E, Mott L. Mortes violentas de LGBT no Brasil: relatório 2018 [Internet]. Salvador: GGB; 2019 [citado 25 Maio 2019]. Disponível em: https:// grupogaydabahia.files.wordpress.com/2020/03/relatorio-2018.pdf

6. Popadiuk GS, Oliveira DC, Signorelli MC. A Política Nacional de Saúde Integral de Lésbicas, Gays, Bissexuais e Transgêneros (LGBT) e o acesso ao Processo Transexualizador no Sistema Único de Saúde (SUS): avanços e desafios. Cienc Saude Colet. 2017; 22(5):1509-20.

7. Sena AGN, Souto KMB. Avanços e desafios na implementação da política nacional de saúde integral LGBT. Tempus. 2017; 11(1):9-28. 
8. Mello L, Perilo M, Braz CA, Pedrosa C. Políticas de saúde para lésbicas, gays, bissexuais, travestis e transexuais no Brasil: em busca de universalidade, integralidade e equidade. Sex Salud Soc. 2011; (9):7-28.

9. Mello L, Brito W, Maroja D. Políticas públicas para a população LGBT no Brasil: notas sobre alcances e possibilidades. Cad Pagu. 2012; (39):403-29.

10. Rocon PC; Rodrigues A, Zamboni JE, Pedrini MD. Dificuldades vividas por pessoas trans sem acesso ao Sistema Único de Saúde. Cienc Saude Colet. 2016; 21(8):2517-26.

11. Vilasbôas AQ, Paim JS. Práticas de planejamento e implementação de políticas no âmbito municipal. Cad Saude Publica. 2008; 24(6):1239-50.

12. Morgan DL. Focus group as qualitative research. London: Sage; 1997.

13. Liamputtong P. Qualitative research methods. 4a ed. Melbourne: Oxford; 2012.

14. Ferraz D, Kraiczyk J. Gênero e políticas públicas de saúde: construindo respostas para o enfrentamento das desigualdades no âmbito do SUS. Rev Psicol Unesp. 2010; 9(1):70-82.

15. 15. Guimarães RCP, Cavadinha ET, Mendonça AVM, Sousa MF. Assistência à saúde da população LGBT em uma capital brasileira: o que dizem os Agentes Comunitários de Saúde? Tempus. 2017; 11(1):121-39.

16. Albuquerque GA, Garcia CL, Alves MJH, Queiroz CMH, Adami F. Homossexualidade e o direito à saúde: um desafio para as políticas públicas de saúde no Brasil. Saude Debate. 2013; 37(98):516-24.

17. Organização Pan-Americana da Saúde. Estigma e discriminação são as principais barreiras à saúde para a população LGBT [Internet]. Brasília: OPAS; 2019 [citado 25 Maio 2019]. Disponível em:_https://www.paho.org/bra/index.php?option=com_co ntent\&view=article\&id=5318:estigma-e-discriminacao-sao-as-principais-barreiras-asaude-para-a-populacao-lgbt\&Itemid $=820$

18. Villela WV, Monteiro SS. Gênero, estigma e saúde: reflexôes a partir da prostituição, do aborto e do HIV/aids entre mulheres. Epidemiol Serv Saude. 2016; 24(3):531-40.

19. Silva LKM, Silva ALMA, Coelho AA, Martiniano CS. Uso do nome social no Sistema Único de Saúde: elementos para o debate sobre a assistência prestada a travestis e transexuais. Physis. 2017; 27(3):835-46.

20. Brasil. Ministério da Saúde. Portaria no 1.820, de 13 de Agosto de 2009. Dispóe sobre os direitos e deveres dos usuários da saúde. Brasília: Ministério da Saúde; 2009.

21. Arán M. A transexualidade e a gramática normativa do sistema sexo gênero. Ágora. 2006; 9(1):49-63.

22. Bezerra DS, Bezerra AK, Souza RCM, Nogueira WBAG, Bonzi ARB, Costa LMM. Homens transexuais: invisibilidade social e saúde mental. Temas Saude. 2018; 18(1):428-44.

23. Prado EAJ, Sousa MF. Políticas públicas e a saúde da população LGBT: uma revisão integrativa. Tempus. 2017; 11(1):69-80.

24. Brasil. Ministério da Saúde. MS lança campanha voltada à saúde dos homens gays e bissexuais [Internet]. Brasília: Ministério da Saúde; 2016 [citado 29 Jul 2019]. Disponível em: http://www.saude.gov.br/noticias/agencia-saude/23381-ms-lancacampanha-voltada-a-saude-dos-homens-gays-e-bissexuais

25. Brasil. Ministério da Saúde. Instrução normativa n.o 2, de 22 de Novembro de 2005. Regulamenta as atividades de vigilância epidemiológica com relação à coleta, fluxo, periodicidade de envio de dados da notificação compulsória de doenças por meio do Sistema de Informação de Agravos de Notificação (SINAN). Diário Oficial da União. 23 Nov 2005. 
26. Araújo MAL, Galvão MTG, Saraiva MMM, Albuquerque AD. Relação usuáriaprofissional de saúde: experiência de uma mulher homossexual em uma unidade de saúde de referência de Fortaleza. Esc Anna Nery. 2006; 10(2):323-7.

27. Brasil. Ministério da Saúde. Secretaria de Gestão Estratégica e Participativa. Relatório do Seminário Nacional de Saúde LGBT, I [Internet]. Brasília: Ministério da Saúde; 2015 [citado 25 Maio 2019]. Disponível em: http://bvsms.saude.gov.br/bvs/ publicacoes/relatorio_semniario_nacional_saude_lgbt.pdf

28. Brasil. Ministério da Saúde. Secretaria de Gestão Estratégica e Participativa. Relatório do Seminário Nacional de Saúde LGBT, I [Internet] Brasília: Ministério da Saúde; 2015 [citado 25 Maio 2019]. Disponível em: http://bvsms.saude.gov.br/bvs/ publicacoes/relatorio_semniario_nacional_saude_lgbt.pdf

29. Negreiros FRN, Ferreira BO, Freitas DN, Pedrosa JIS, Nascimento EF. Saúde de lésbicas, gays, bissexuais, travestis e transexuais: da formação médica à atuação profissional. Rev Bras Educ Med. 2019; 43(1):23-31.

30. Cardoso MR, Ferro LF. Saúde e população LGBT: demandas e especificidades em questão. Psicol Cienc Prof. 2012; 32(3):552-63.

31. Carvalho LS, Philippi MM. Percepção de lésbicas, gays e bissexuais em relação aos serviços de saúde. Universitas Cienc Saude. 2013; 11(2):83-92.

32. Brasil. Ministério da Saúde. Secretaria de Gestão Estratégica e Participativa. Cuidar bem da saúde de cada um: faz bem para todos: faz bem para o Brasil: atenção integral à saúde de homens gays e bissexuais: conteúdo para profissionais de saúde / trabalhadores do SUS [Internet]. Brasília: Ministério da Saúde; 2016 [citado 20 Maio 2019]. Disponível em: http://bvsms.saude.gov.br/bvs/publicacoes/homens_gays_ bissexuais_direitos_saude.pdf

33. 33. Facchini R, Barbosa RM. Dossiê saúde das mulheres lésbicas: promoção da equidade e da integralidade. Belo Horizonte: REDESAÚDE; 2006.

34. Secretaria da Saúde do Estado do Paraná. Secretaria de Estado da Saúde realiza testes rápidos de HIV no centro de Curitiba [Internet]. Curitiba: Secretaria da Saúde; 2018 [citado 20 Jun 2019]. Disponível em: http://www.saude.pr.gov.br/modules/noticias/ article.php? storyid $=6402$

35. Brasil. Ministério da Saúde. Departamento de DST, Aids e Hepatites Virais Secretaria de Vigilância em Saúde. A experiência do Departamento de DST, Aids e Hepatites Virais Secretaria de Vigilância em Saúde Ministério da Saúde [Internet]. Brasília: Ministério da Saúde; 2012 [citado 20 Maio 2019]. Disponível em:_http://bvsms.saude. gov.br/bvs/periodicos/resposta_2012.pdf

36. Paraná (Estado). Resolução SEJU n 149, de 7 de Dezembro de 2015. Institui o Comitê de Acompanhamento da Política de Promoção e Defesa dos Direitos de Lésbicas, Gays, Bissexuais, Travestis e Transexuais do Estado do Paraná. Diário Oficial do Estado do Paraná. 14 Dez 2015. n. 9596.

37. Paraná (Estado). Resolução SESA no 56, de 18 de Fevereiro de 2015. Institui o Comitê Técnico de Saúde Integral das Pessoas LGBT, no âmbito da saúde. Diário Oficial do Estado do Paraná. 20 Fev 2015. n. 9395.

38. Signorelli MC, Azevedo ACS, Cortiano SW, Walhrich DFG, Peres EL, Amaral C, et al. Relatório técnico de análise qualitativa de implementação da Política Nacional de Saúde Integral da População LGBT no Estado do Paraná. Porto Alegre: UFRGS; 2019. 
State of Parana, Brazil, through

The article addresses an urgent and relevant theme: the challenges and potentialities for the implementation of public health policies targeted at the LGBT population. We investigated the implementation of the National Policy for the Comprehensive Healthcare of Lesbians, Gays, Bisexuals, Transvestites and Transsexuals (PNSI LGBT) in the State of Parana, Brazil, through four focus groups with 48 participants, in a qualitative approach. The groups were formed by professionals and managers of the Brazilian National Health System and of the Health Department of the State of Paraná, professionals with the intersectoral network, and representatives of LGBT social movements. Four analysis axes were established: the LGBT population's access to comprehensive care; health promotion and surveillance actions; permanent health education and popular health education; monitoring and assessment of health actions. We concluded that there are gaps in the implementation of the policy in the three levels of the healthcare provided for the LGBT population.

Keywords: Public policy. Health equity. LGBT people. Brazilian National Health System.

El artículo trata de un tema urgente y relevante referente a los desafíos y potencialidades para la implementación de políticas públicas destinadas a la población LGBT. Se investigó la implementación de la Política Nacional de Salud Integral de Lesbianas, Gais, Bisexuales, Travestis y Transexuales (PNSI LGBT) en el Estado de Paraná, Brasil, por medio de cuatro grupos focales con 48 participantes, con un abordaje cualitativo. En los grupos participaron profesionales y gestores (as) del Sistema Brasileño de Salud, de la Secretaría de la Salud del Estado de Paraná, profesionales de la red intersectorial y representantes de movimientos sociales LGBT. Se definieron cuatro ejes de análisis: acceso de la población LGBT a la atención integral de la salud; acciones de promoción y vigilancia en salud; educación permanente y educación popular en salud; monitoreo y evaluación de las acciones de salud. Se concluyó que hay lagunas en la implementación de la política en los tres niveles de atención de la salud de la población LGBT.

Palabras clave: Política pública. Equidad en salud. Personas LGBT. Sistema Brasileño de Salud. 